\title{
Representações sociais sobre suicídio
}

\author{
Social representations about suicide
}

Representaciones sociales acerca del suicidio

Recebido: $17 / 11 / 2020$

Aprovado: 21/03/2020

Publicado: 14/04/2021

\author{
Otávio Henrique Braz de Oliveira Calile ${ }^{1}$ \\ Daniela Scheinkman Chatelard ${ }^{2}$
}

Essa é uma pesquisa quali-quantitativa, realizada em 2019, em Brasília, DF, com objetivo de verificar e descrever as representações sociais de estudantes de psicologia sobre o suicídio. Utilizou-se questionários de evocação com justificativas em campo livre. Os dados foram interpretados com procedimentos estatísticos propostos pela Análise Prototípica. Participaram 170 acadêmicos do segundo ao quarto período, de uma universidade privada. Os estudantes tinham entre 18 e 50 anos, sendo $89 \%$ mulheres e $11 \%$ são homens. Dentre os principais valores: Classe 1: 19,6\%; Classe 2:14,44; Classe 3:26,1; Classe 4:26,8 e Classe 5:13,1); e, os dados provenientes de entrevistas permitiram a construção de duas categorias: Depressão e suporte social e, Sofrimento e fraqueza. As representações sociais do suicídio para os estudantes de psicologia são estruturadas com fundamento nos seguintes elementos do núcleo central: morte, dor, sofrimento, depressão, medo, pressão e tristeza. Entretanto, quando os participantes são instados a evocar termos que atribuem aos colegas, os elementos pressão e medo não aparecem mais, surgindo, então, a palavra fraqueza.

Descritores: Suicídio; Psicologia Social; Depressão.

This is a qualitative-quantitative research, carried out in 2019, in Brasília - DF, Brazil. It aimed to verify and describe the social representations of psychology students about suicide. Evocation questionnaires with justification in the free field were used. The data were interpreted with statistical procedures proposed by the Prototypical Analysis. The participants were 170 academics from the second to the fourth period, from a private university. The students were between 18 and 50 years old, $89 \%$ were women and 11\% were men. Among the main values: Class 1: 19.6\%; Class 2: 14.44; Class 3: 26.1; Class 4: 26.8 and Class 5: 13.1); and, the data from interviews allowed the construction of two categories: Depression and social support and Suffering and weakness. The social representations of suicide for students of psychology are structured based on the following elements of the central nucleus: death, pain, suffering, depression, fear, pressure and sadness. However, when participants are asked to evoke terms that they attribute to colleagues, the elements of pressure and fear no longer appear, but the word weakness does.

Descriptors: Suicide; Social Psychology; Depression.

Esta es una investigación cuali-cuantitativa, realizada en 2019, en Brasilia, DF, Brasil, con el objetivo de verificar y describir las representaciones sociales de los estudiantes de psicología acerca del suicidio. Se utilizaron cuestionarios de evocación con justificaciones en campo libre. Los datos se interpretaron con los procedimientos estadísticos propuestos por el Análisis Prototípico. Participaron 170 académicos del segundo al cuarto periodo de una universidad privada. Los estudiantes tenían entre 18 y 50 años, siendo el 89\% mujeres y el $11 \%$ hombres. Entre los principales valores: Clase 1: 19,6\%; Clase 2: 14,44; Clase 3: 26,1; Clase 4: 26,8 y Clase 5: 13,1); y, los datos de las entrevistas permitieron la construcción de dos categorías: Depresión y soporte social, y Sufrimiento y debilidad. Las representaciones sociales del suicidio para los estudiantes de psicología se estructuran a partir de los siguientes elementos del núcleo central: muerte, dolor, sufrimiento, depresión, miedo, presión y tristeza. Sin embargo, cuando se pide a los participantes que evoquen los términos que atribuyen a sus colegas, ya no aparecen los elementos presión y miedo, y entonces aparece la palabra debilidad.

Descriptores: Suicidio; Psicología Social; Depresión.

1. Pedagogo. Bacharel em Letras. Especialista em Psicopedagogia Clínica e Institucional. Mestre em Processos de Desenvolvimento Humano e Saúde. Doutor em Psicologia Social, do Trabalho e das Organizações. Pós Doutor em Psicologia Clínica e Cultura. Gestor e pesquisador do Instituto Kalile de Desenvolvimento Humano e Pesquisa, Brasília, DF, Brasil. ORCID: 0000-0001-7535-6325 E-mail: otavio.calile@gmail.com 2. Psicóloga. Mestre em Psicanálise. Doutora em Filosofia. Pós Doutora em Psicologia Escolar e do Desenvolvimento Humano, Professora Associada da Universidade de Brasília, DF, Brasil. ORCID: 0000-0002-7925-573X E-mail: dchatelard@gmail.com 


\section{INTRODUÇÃO}

$\mathbf{0}$ suicídio é uma manifestação transcultural sujeita a valorações ambivalentes e marcado por significados que variam ao longo da história. É definido como um ato intencionalmente executado pelo próprio indivíduo contra si mesmo, por meio de determinadas ações com vistas à sua morte ${ }^{1,2}$.

A gênese do suicídio é multideterminada e incluem as ideações, os pensamentos e o desejo de morte ${ }^{3,4}$. Essas manifestações evoluem para a tentativa, precedida, na maioria das vezes, por um plano que carrega significados subjetivos ${ }^{5}$. Em virtude da complexidade de sua manifestação, constitui-se de uma intrincada trama de fatores biológicos e psicossociais envolvidos na ideia e no ato ${ }^{6-8}$.

Durkheim" definiu o suicídio como "todo o caso de morte que resulta direta ou indiretamente de um ato positivo ou negativo praticado pela própria vítima, ato que a vítima sabia dever produzir este resultado" e, a partir do estudo de casos particulares a partir de leis universais, também delimita o estudo sociológico do tema, argumentando que o suicídio é um fato social com a gênese na constituição das sociedades. Por meio do conceito de representações coletivas - entendidas como uma forma de consciência social partilhada - se estabelece que o estudo do suicídio deve ir além das causalidades individuais, as quais pertenceriam ao campo da psicologia 9 .

Em todo o mundo, o número de suicídios tem se elevado continuamente, ultrapassando 800 mil casos por ano. No ano de 2020, os suicídios representaram 2,4\% do total de mortes no mundo, com predominância em países em desenvolvimento ${ }^{10}$.

Na realidade brasileira, estima-se que em torno de $17 \%$ das pessoas já tiveram ideações suicidas alguma vez na vida11. 0 país está em $8^{\text {o }}$ lugar na posição de países com mais casos de suicídio segundo a Organização Mundial de Saúde ${ }^{12}$, sendo que, entre 2002 e 2012, o número de casos aumentou em 36\% em todo o país. Foram 106.374 casos de autoextermínio no Brasil entre 2007 e 2016, de modo que uma pessoa morre a cada 45 minutos, totalizando 32 suicídios por dia ${ }^{13}$.

Esses números impactam profundamente uma sociedade em diversas dimensões que ultrapassam a esfera da saúde pública. Embora sejam números alarmantes, estima-se que as tentativas de suicídio ultrapassam em 10 vezes a consumação do ato ${ }^{14}$. 0 aumento de suicídios afeta toda a sociedade, com consequências drásticas no âmbito da economia, das relações interpessoais e familiares e da saúde física e psíquica das pessoas envolvidas ${ }^{3,14-16}$.

Nesse cenário, a pesquisa científica em suicidologia encontra muitos obstáculos, devido aos tabus e interdições suscitados pela temática ${ }^{17}$. Ademais, essas pesquisas não têm contribuído com a diminuição da incidência do número de casos no mundo devido ao crescimento desordenado de casos e as dificuldades estatísticas de registro ${ }^{12,14}$. Uma das causas para essas dificuldades no âmbito da investigação científica reside no fato de que as pesquisas dessa área costumam analisar e discutir dados sobre pensamentos, ideações, autolesões e tentativas de suicídio indistintamente ${ }^{18}$. Os trabalhos que não misturam esses aspectos possibilitam uma análise mais refinada e admitem encaminhamentos menos generalizados ${ }^{19-}$ 22.

A temática do suicídio é marcada por proibições, tabus e preconceitos dirigidos aos sujeitos e às suas famílias ${ }^{1,14,16,23}$. As pesquisas mostram que o impacto de um ato suicida é muito alto para os sobreviventes, estimando-se que entre 5 e 10 familiares e amigos são afetados por esse acontecimento. A partir desse ato, essas pessoas passam a fazer parte do grupo de risco, haja vista que os sentimentos relatados mais frequentes são o estigma social, abandono, vergonha e culpa ${ }^{2,7,13,14,24}$.

Assim como as famílias de pessoas mortas em decorrência do HIV no fim do século XX, os familiares de suicidas sentem-se desamparados e com uma forte sensação de fracasso, principalmente quando se trata de mães e esposas. Eles sentem que seu sofrimento não é reconhecido, pois o assunto é marcado por crenças tácitas de interdição. Essa impossibilidade 
de compartilhar seus sofrimentos dificulta o acesso ao suporte social para que o processo de luto seja vivenciado adequadamente, o que evitaria o risco de novos suicídios entre os sobreviventes ${ }^{25,26}$.

Fundados nessas questões e na perspectiva da compreensão do repertório de psicólogos em formação acerca dessa temática, recorreu-se à Teoria das Representações Sociais (TRS) ${ }^{27}$ e seus desdobramentos metodológicos 28 .

Moscovici27 criou a TRS baseando-se no conceito de representações coletivas proposto por Durkheim ${ }^{9}$. A investigação sobre os processos psicológicos subjacentes à elaboração subjetiva dos modelos sociais é recente na psicologia. É a emergência do estudo de um fenômeno que antes era estudado apenas como conceito. Essa mudança de concepção epistemológica acerca das representações permite, a psicologia social explicá-las sobre o ponto de vista empírico.

Assim, as representações sociais (RS) estão na interface entre o individual e o coletivo, acentuando o caráter psicológico de sua estrutura na medida em que os símbolos partilhados pelo grupo são mediados e internalizados pelos indivíduos, tornando-se constitutivo da essência desse mesmo grupo e organizando psicologicamente seu cotidiano ${ }^{29}$.

As RS situam-se na interface do psicológico e do social, sob a forma de conhecimentos elaborados e compartilhados socialmente que contribuem para a construção de uma realidade comum, possibilitando a compreensão e a comunicação do sujeito no mundo. As RS vinculamse a valores, noções e práticas individuais que orientam as condutas no cotidiano das relações sociais e se manifestam através de estereótipos, sentimentos, atitudes, palavras, frases e expressões. É um conhecimento do "senso comum", socialmente construído e partilhado, diferente do conhecimento científico, que é reificado e fundamentalmente cognitivo ${ }^{30}$.

"As pessoas que interrogamos dizem o que pensam?". Abric ${ }^{28}$ refletiu sobre a confiabilidade dos dados das pesquisas em RS, pois há a possibilidade de os participantes não revelarem as verdadeiras representações. Esse fenômeno ocorre principalmente com pesquisas cujas temáticas são de natureza sensível e com conteúdo reificados por diversos discursos sociais interditados, como é a temática do suicídio.

As RS são extraídas por meio de discursos sociais mediados pela cultura e são permeados de interdições, negociações e desejabilidade sociais. São discursos que estão articulados com as normas sociais e com as características do grupo que fazem parte. Por conta disso, é possível que haja uma defasagem entre o que as pessoas pensam e o que elas escrevem nos questionários de pesquisa. Dessa forma, a estratégia deliberada dos respondentes consiste em esconder "alguns componentes de seus pensamentos em certas situações, e nestas existem duas facetas da representação: uma, explícita, verbalizada; outra não verbalizada, não expressa, denominada zona muda"31.

O conteúdo da zona muda das RS é contra normativo, pois expressa o pensamento que as pessoas acreditam que deveriam ter para estarem de acordo com determinados discursos sociais que consideram hegemônicos sobre o tema pesquisado. Essas cognições, se fossem expressas abertamente, poderiam contrariar os valores sociais e morais de grupos, e isso ameaça a ideia do pertencimento. Por isso as pessoas tendem a não dizer tudo o que pensam sobre determinados temas considerados sensíveis no contexto sociais que pertencem ${ }^{31}$.

Tendo o suicídio como um desses temas socialmente sensíveis, uma pesquisa sobre RS do suicídio e depressão ${ }^{32}$ com 233 estudantes de psicologia mostrou que as RS tinham elementos como: doença, desilusão, angústia e desequilíbrio, considerando-se de modo indistinto depressão e suicídio no mesmo campo semântico.

Considerando a discussão pública contemporânea sobre os aumentos de casos de suicídio no Brasil e no mundo $7,12,33$ e, tendo em vista a relevância dessa temática para a área da psicologia e da saúde mental, emerge, então, a seguinte questão: De que forma o suicídio é representado pelos profissionais da psicologia no curso de sua formação? Assim, este estudo tem 
como objetivo verificar e descrever as representações sociais de estudantes de psicologia sobre o suicídio.

\section{MÉTODO}

Essa pesquisa de caráter quali-quantitativo foi dividida em dois estudos articulados: o estudo 1 aborda as representações sociais em 1 a pessoa, ao passo que o estudo 2 refere-se às representações sociais por meio da técnica projetiva da zona muda.

Para a inclusão da amostra, os participantes deveriam estar regulamente matriculados no curso de Psicologia de uma universidade privada de Brasília. Os estudantes matriculados no $1^{\circ}$ semestre do curso foram excluídos da amostra. A coleta de dados se iniciou após algumas orientações (anonimato e o sigilo das informações, além da utilização dos resultados exclusivamente para contribuições científicas), explicação da proposta do estudo, bem como a assinatura do Termo de Consentimento Livre e Esclarecido (TCLE), Todos responderam individualmente, sem qualquer comunicação entre colegas.

Aplicou-se um questionário de evocação baseado na técnica de associação livre ${ }^{29}$, que permite que os participantes evoquem o que têm em mente quando se deparam com o termo indutor, isto é, o objeto representacional.

Para o estudo 1, o questionário de evocação possibilitou a associação livre de ideias acerca do o termo indutor proposto: Quais as primeiras palavras ou ideias que lhe vem à cabeça sobre suicídio? Assim, a partir desse termo indutor, o participante escreveu, em campo específico, 6 (seis) palavras ou expressões, classificando-as, em seguida, por ordem de importância, atribuindo o número 1 (um) à palavra mais importante e 6 (seis) à menos importante. Na sequência, o participante justificou a escolha da palavra mais importante em um campo aberto.

Para o estudo 2 referente à zona muda, se utilizou a técnica da substituição ${ }^{31}$, repetindo os mesmos procedimentos a partir do seguinte termo indutor: Quais as primeiras palavras ou ideias que você acha que vem à cabeça dos seus colegas de curso quando eles pensam sobre suicídio? A explicação da palavra que melhor se associa ao termo indutor permitiu qualificar a resposta buscando o seu sentido no contexto das palavras evocadas ${ }^{32}$.

A análise prototípica foi a técnica utilizada para a organização da estrutura das representações ${ }^{35}$. Para isso, foi utilizado o programa computacional Iramuteq. 0 procedimento de análise é desenvolvido com base no cálculo da frequência e da ordem média das evocações e da formulação de categorias formadas pela frequência, composições e co-ocorrências.

Por meio da análise prototípica, buscou-se a relação objeto-cognema a partir de dois critérios fundamentais de acessibilidade do elemento cognitivo: a frequência e a velocidade da evocação pelos grupos fornecida pela ordem média de importância atribuída à expressão. Esse cálculo é feito por meio da média ponderada dos graus de importância ${ }^{34}$.

O duplo sistema formado pelos possíveis elementos centrais e periféricos são dados pela identificação da relevância dos elementos associados ao termo indutor. As correspondências entre esses critérios permitem uma análise estrutural das representações, vislumbrando-se o conteúdo e a organização interna. Várias pesquisas têm sido realizadas majoritariamente por meio de softwares para o suporte de análise de conteúdo ${ }^{34,35}$.

\section{RESULTADOS}

Os estudos foram conduzidos com a participação voluntária de 170 estudantes de psicologia do $2^{2}$ a a $4^{\text {o }}$ período de uma faculdade particular de Brasília. A idades dos participantes estão distribuídas da seguinte forma: entre 18 e 30 anos (n=21); entre 31 e 40 anos $(n=27)$ e entre 40 e 50 anos $(n=22)$. Sobre o gênero dos participantes, $89 \%$ são mulheres e $11 \%$ são homens.

0 resultado da Análise Pós-Fatorial (AFP) mostrou a frequência das palavras (F) e a ordem média de evocação (OME). Quanto menor o índice de OME, mais rapidamente o participante 
lembrou da palavra. As palavras evocadas serão apresentadas juntamente com suas frequências e OME em parênteses (frequência/ordem média de evocação).

Os resultados dessa análise no Estudo 1 revelam que os estudantes representam o suicídio a partir do termo morte $(21 ; 2,5)$ e de outras expressões relacionadas: dor $(59 ; 2,6)$, sofrimento $(42 ; 2,7)$, depressão $(92 ; 2,9)$, medo $(32 ; 3,1)$, pressão $(21 ; 3,2)$ e tristeza $(71 ; 3,2)$. No que se refere à zona muda, observou-se que não apareceram os termos medo e pressão no núcleo central (Tabela 2). No entanto, o termo fraqueza $(27 ; 2,9)$ figurou nesse quadrante.

A Classificação Hierárquica Descendente (CHD), feita como o corpus textual das justificativas dos participantes, forneceu um dendograma com classes de palavras, cujo quiquadrado ultrapassou $X^{2}>12,52$. Verificou-se os principais elementos de cada classe e o percentual de Unidades de Contexto Elementar (UCEs) que elas partilham. Essa análise possibilita a formulação de categorias formadas pela frequência, composições e co-ocorrências.

A análise, assim com as justificativas de classe de palavras (C1, C2, C3, C4, C5), estudo (E1 ou E2) estão nas Tabelas 1 e 2, bem como o escore da justificativa que representa a relevância da fala para a classe em questão. Optou-se por apresentar as justificativas que obtiveram os maiores escores. 
Tabela 1. Análise Prototípica do Estudo 1 realizada com 170 estudantes de Psicologia de uma universidade privada. Brasília, 2019.

\begin{tabular}{|c|c|c|c|c|c|c|c|c|c|}
\hline \multicolumn{2}{|c|}{ Classe $1(19,6 \%)$} & \multicolumn{2}{|c|}{ Classe $2(14,44 \%)$} & \multicolumn{2}{|c|}{ Classe $3(26,1 \%)$} & \multicolumn{2}{|c|}{ Classe $4(26,8 \%)$} & \multicolumn{2}{|c|}{ Classe $5(13,1 \%)$} \\
\hline Palavras & Classe 1 & Palavras & Classe 2 & Palavras & Classe 3 & Palavras & Classe 4 & Palavras & lasse 5 \\
\hline Achar & 23,4 & Depressão & 48,365 & Melhor & 31,574 & Falta & 15,857 & Viver & 56,57 \\
\hline dever & 21,193 & Principal & 24,458 & Definir & 25,156 & Tirar & 15,438 & Vontade & 12,177 \\
\hline Situação & 20,337 & Fato & 24,118 & Palavra & 23,516 & Nível & 14,12 & Triste & $: 4,172$ \\
\hline Estar & 18,659 & Sentimento & 23,357 & Dor & 18,614 & Chegar & 13,476 & Perder & $? 0,736$ \\
\hline Pensar & 16,724 & Sair & 18,221 & Busca & 17,642 & Grande & 12,981 & Parecer & $? 0,376$ \\
\hline Família & 16,088 & Fator & 18,221 & Fugir & 17,642 & Ponto & 12,669 & Mundo & $\lfloor 3,863$ \\
\hline Difícil & 12,546 & Estado & 18,079 & Matar & 16,072 & Tentar & 11,611 & Humano & $\lfloor 3,863$ \\
\hline Frescura & 12,546 & Doença & 13,868 & Tentativa & 14,602 & Desistir & 10,175 & Sentar & $\lfloor 2,031$ \\
\hline Coisa & 9,852 & Maioria & 13,868 & Representar & 13,482 & Lutar & 8,359 & Ficar & $\lfloor 0,018$ \\
\hline Existir & 9,852 & Tomar & 8,738 & Suicídio & 13,189 & Saída & 8,2 & Vazio & $\lfloor 0,018$ \\
\hline
\end{tabular}

Tabela 2. Análise Prototípica do Estudo 2 realizada com 170 estudantes de Psicologia de uma universidade privada. Brasília, 2019.

\begin{tabular}{|c|c|c|c|c|c|c|c|}
\hline Classe 1 & & Classe 2 & & Classe 3 & & Classe 4 & \\
\hline Palavra & Classe 1 & Palavra & Classe 2 & Palavra & Classe 3 & Palavra & Classe 4 \\
\hline Depressão & 43,335 & Sentar & 18,865 & Colega & 25,51 & Problema & 22,439 \\
\hline Levar & 22,911 & Vida & 18,11 & Acreditar & 18,315 & Cometer & 22,188 \\
\hline Doença & 16,565 & Saída & 16,396 & Coisa & 17,597 & Dizer & 19,878 \\
\hline Suicídio & 13,732 & Acabar & 15,426 & Estar & 13,73 & Ouvir & 18,865 \\
\hline Estudar & 11,714 & Próprio & 9,641 & Ajudar & 9,151 & Familiar & 12,984 \\
\hline Escolher & 11,714 & Sofrimento & 8,573 & Acontecer & 9,151 & Fossar & 9,641 \\
\hline Tipo & 7,86 & Ideia & 6,23 & Passar & 5,604 & Fraco & 9,641 \\
\hline Ir & 5,111 & Só & 6,23 & Fazer & 4,802 & Pessoa & 6,777 \\
\hline \multirow[t]{2}{*}{ Pensar } & 3,973 & Ver & 6,23 & Pensar & 4,412 & Ser & 6,777 \\
\hline & & Dor & 6,23 & & & Querer & 6,141 \\
\hline estar & $-9,586$ & Suicídio & $-7,53$ & Depressão & $-8,996$ & Pensar & $-4,353$ \\
\hline vida & $-7,233$ & Colega & $-6,991$ & Problema & $-5,024$ & & \\
\hline acreditar & $-5,756$ & Depressão & $-5,662$ & & & & \\
\hline querer & $-4,375$ & Acreditar & $-5,193$ & & & & \\
\hline
\end{tabular}


A partir das UCEs, foram construídas duas categorias, a saber: Depressão e suporte social e Sofrimento e fraqueza.

\section{Depressão e suporte social}

No Estudo 1, a estrutura do dendograma obtido por meio da CHD aponta que as Classes 1 e 2 estão interligadas, indicando que seus dados devem ser analisados de forma articulada. A Classe 1 apresenta 19,6\% de UCEs e traz termos que demonstram o papel da família e do círculo social para o suporte ou para o agravamento do risco dos indivíduos potencialmente suicidas.

Nessa categoria, o suicídio é representado como uma decorrência da solidão advinda da desqualificação do sofrimento psíquico pelas pessoas, de acordo com o meio social no qual o indivíduo está inserido. Quando esse sofrimento não é reconhecido pelo outro, as pessoas encontrariam o suicídio como solução a essa demanda insatisfeita. Essa representação pode ser evidenciada nas falas abaixo:

Porque uma pessoa que tem depressão e pensa em suicídio nunca é compreendida pela família, amigos e colegas, pois muitos acabam achando que esse sofrimento é frescura ou só uma fase difícil que a pessoa está passando. (C1, E1); Participante 144

Porque para a pessoa quer se suicidar ela deve estar passando por algum momento difícil sofrendo por alguma situação ou achando que ninguém liga para existência dela se sentindo sozinha. (C1, E1); Participante 9

Porque quando a pessoa pensa em suicídio, ela está passando por algo ruim na vida; se sente abandonada por seus amigos familiares, não tem apoio que necessariamente precisa naquele momento. Isso reforça a ideia não está sendo valorizado. (C1, E1); Participante 67

Acho que no momento de total desespero do indivíduo o leva a praticar tal ato sem pensar direito ou quando este pode estar achando que não há mais salvação ou que está sozinho onde não há ninguém para ajudar ou que está sem a solução dos seus problemas. (C1, E1); Participante 62

Porque acho que quando uma pessoa está pensando em se suicidar ela deve estar muito desesperada por algum motivo que talvez ela ache que não tem solução daí com outros sentimentos ela pensa no suicídio. (C1, E); Participante 118

A Classe 2 do Estudo 1 apresenta 14,4\% de UCEs. 0 conteúdo dessa categoria mostra que os participantes ancoraram o suicídio como uma manifestação de um estado de depressão no qual os indivíduos estão acometidos. Em articulação com os resultados obtidos na Classe 1 desse mesmo estudo, da qual se infere que o suporte social da família e de pessoas próximas é essencial para a prevenção desse estado de depressão e de seu consequente ato suicida. Nas falas com escores mais altos, o suicídio é representado como o decurso de uma doença de origem psíquica que vem "de dentro para fora" e que se caracteriza pelo desespero e pela impossibilidade de resolução por meio de palavras.

Porque reflete a doença, e o fato de a pessoa não conseguir lidar com ela sozinha; o sentimento de desamparo causado pela depressão irá trazer o desespero, levando ao suicídio como resolução dos problemas. (C2, E1); Participante 89 Quando se está com depressão, nada tem cor. Você acha que algum dia sairá daquilo. Palavras não ajudam porque você não tem esperança que de alguma forma o sentimento passará, que você mudará que a esperança ressurgirá e que as coisas de fato melhorarão. (C2, E1); Participante 143

A depressão é uma doença que consome o ser vem de dentro para fora silenciosamente e quando vê estamos em um buraco tentando sair, porém não conseguimos o fato de ser tão doloroso e sofrido gera uma alta taxa de suicídio. (C2, E1); Participante 83

A depressão, porque é uma séria doença, que se não for tratada pode levar ao suicídio; também acho que essa é a principal causa do suicídio. (C2, E1); Participante 17

Em relação à perspectiva no estudo da zona muda, a Classe 1 do Estudo 2 (25,2\% de UCEs) apresenta resultados semelhantes com o conteúdo da Classe 2 do Estudo 1, tendo em vista que em ambas o suicídio foi representado como um fenômeno mórbido decorrente da depressão. Entretanto, os resultados obtidos na zona muda revelam críticas à hiperpatologização de aspectos cotidianos e à atribuição demasiada de causalidade ao estado de depressão como uma doença deflagradora do suicídio. Nas falas a seguir, podemos observar a produção de sentido dos participantes sobre esses aspectos:

Hoje em dia tudo gira em torno da depressão. A doença do século sempre ronda nossas conversas: se você tirar nota ruim, é porque estava deprimido e não estudou; se você se isola, está deprimido; se você ficou doente, ficou porque 
está deprimido. (C1, E2); Participante 24

A maioria das pessoas devem colocar depressão como resposta, mas acabam esquecendo que tudo que foi escrito pode levar à depressão e consequentemente ao suicídio. (C1, E2); Participante 81

\section{Sofrimento e fraqueza}

A classe 5 do Estudo 1 partilhou 13,1\% das UCEs. A estrutura do dendograma obtido pela CHD aponta que seus conteúdos devem ser analisados de forma articulada com os da Classe 4. Nessa categoria, o suicídio é representado como a decorrência de um vazio existencial que leva as pessoas a não terem mais sentido para suas vidas.

As representações dessa categoria aparecem em expressões como isolamento, solidão, perda e tristeza. Esse quadro contribuiria para o estado de isolamento, desamparo e de frustração devido a insuficiência resultante do não cumprimento das expectativas sociais: Essa ideia de vazio se relaciona com a incapacidade de lidar com a pressão social e as cobranças:

A solidão e o vazio fazem o ser humano perder a vontade de viver. (C5, E1); Participante 147

Quando uma pessoa está depressiva, ela se sente muito vazia e triste, então nada anima e ela perde a graça de viver porque parece que nada é suficiente. (C5, E1); Participante 74

No isolamento, a pessoa não tem vontade de nada, perde toda a vontade de se alimentar, tomar banho se relacionar; um vazio enorme, onde parece a morte vai trazer um escape para tudo isso. (C5, E1); Participante 144

O sujeito vive em sociedade e isso é natural. A partir do momento que ele não suporta as cobranças, não consegue realizar atividades simples do dia-a-dia, não é aceito ou não consegue aprovação de um determinado grupo social. Enfim, o isolamento é muito triste, pois ninguém vive sozinho. (C5, E1); Participante 63

A Classe 4 do Estudo 1 apresenta o maior percentual de UCEs, com um total de 26,8\%. Infere-se que os participantes representam o suicídio como uma falta de vontade de viver. Os termos falta e tirar pertencem a campos semânticos semelhantes, indicando que a falta é objetivada no ato de tirar a vida. Para os estudantes, o nível de tristeza e de falta de esperanças chega a tal ponto, que a saída encontrada é desistir de lutar e, assim, tentar o suicídio. As justificativas dos participantes abaixo mostram como essas representações são organizadas para a formação de sentido:

Creio que uma pessoa para chegar a este ponto de tirar a própria vida já esgotou todo o seu emocional, não vê mais nenhuma solução e com isso o desespero é grande ninguém a entende nem ela mesmo. (C4, E1); Participante 95

A dor é o que as pessoas carregam por frustações, mágoas, falta de perdão, entre outros, e isso não sendo tratado, chega uma hora que sufoca ao ponto de não se acreditar que isso não tem mais jeito. (C4, E1); Participante 141 Porque para uma pessoa chegar a um nível de sofrimento ao ponto de tentar o suicídio ela ele precisa estar muito angustiada sufocada sem esperanças e não pensar mais em nada. (C4, E1); Participante 16

A Classe 3 do Estudo 1 (26,1\% de UCEs) apresenta conteúdos que apontam que os estudantes representam o suicídio como um meio de lidar com seus sentimentos e não como uma finalidade em si mesma. Os participantes empregaram o termo fuga, afirmando que a morte não era necessariamente a meta do ato, mas sim o caminho para uma outra situação diferente dos estados emocionais que emergiram nas classes comentadas anteriormente isolamento, solidão, perda e tristeza e desespero. Assim como na Classe 4 do Estudo 1, a saída é desistir de lutar e tirar a própria vida. Os trechos abaixo apontam essa perspectiva:

Acredito que dor seja a melhor palavra para definir o suicídio porque é o que a maioria dos suicidas relata em suas cartas de despedida para eles a morte é uma forma de acabar com todo o sofrimento que atormenta suas mentes. (C3, E1); Participante 77

Para mim, a fuga define melhor pois eu vejo o suicídio como um escape uma forma da pessoa encontrar para fugir da sua dor que é tão intensa. (C3, E1); Participante 109

Pela dificuldade que a pessoa sente, a depressão é uma maneira de acabar seu sofrimento. (C2, E2); Participante 69 Porque se sente sozinha ou esteja passando por um momento de sofrimento. (C2, E2); Participante 35

Esses mesmos resultados foram encontrados na Classe 2 do Estudo 2 (24,3\% de UCEs). Os estudantes também atribuíram aos colegas a ideia de que o suicídio se constitui como um ato mediador entre o estado de sofrimento atual e um outro estado não objetivado. Entretanto, os resultados encontrados na Classe 4 da zona muda (24,3\% de UCEs) revelam a representação de que essa saída é considerada um ato de fraqueza diante dos problemas e das pressões provenientes do meio social. Esses resultados convergem com aqueles obtidos pela Análise PósFatorial, cujos quadrantes revelaram a fraqueza como um dos elementos que compõe o núcleo central das RS no estudo da zona muda (Tabela 2). Nas falas abaixo, se observa essa posição: 
Eu já ouvi pessoas dizendo que quem comete suicídio é fraco poderia tentar resolver os problemas. (C4, E2); Participante 73

Sempre os ouço dizer que quem comete o ato é alguém fraco. [C4, E2,116] É comum ouvir de outras pessoas a associação de uma pessoa fraca a uma pessoa que comete suicídio é como se o suicídio fosse resumido a falta de força de vontade de alguém. (C4, E2); Participante 52

Pelo que já ouvi dos colegas em algumas conversas em sala sobre o assunto, acredito que a palavra mais citada foi fuga, porque dizem que é uma forma de não sentir mais nada; quem se submete ao suicídio realmente fugir dos problemas do dia a dia. (C4, E2); Participante 164

\section{DISCUSSÃo}

Os resultados obtidos nesse trabalho permitem afirmar que as representações sociais do suicídio para os estudantes de psicologia são estruturadas com fundamento nos seguintes elementos do núcleo central: morte, dor, sofrimento, depressão, medo, pressão e tristeza. Entretanto, quando os participantes são instados a evocar termos que atribuem aos colegas, os elementos pressão e medo não aparecem mais, surgindo, então, a palavra fraqueza. Da mesma forma, ainda que os estudantes associem o suicídio aos aspectos disposicionais (depressão, tristeza e sofrimento), o termo pressão sugere que, para eles, o suicídio também tem uma dimensão social externa ao indivíduo, já que relacionam o suicídio à fraqueza em decorrência da pressão social.

Com relação às representações de estudantes de psicologia sobre essa temática, estudos mostram que há uma crença entre as abordagens psicológicas de que o suicídio é um ato que visa encerrar um sofrimento psíquico insuportável pelo sujeito, que não encontra outras maneiras de conviver com a angústia que o perturba ${ }^{15,36}$. Resultados semelhantes foram encontrados em outra pesquisa ${ }^{31}$, na qual o elemento morte foi representado como uma fuga das adversidades provenientes do meio externo. Percebeu-se, também, que os estudantes ancoraram o suicídio em suas experiências acadêmicas, fundamentando suas representações sobre esse tema em sintomas clínicos e na ideia de saúde mental como equilíbrio emocional.

O suicídio foi representado como decorrência da depressão clínica e como um ato que não visa necessariamente a morte. Nessa direção, outro trabalho ${ }^{37}$ também mostrou a representação do suicídio como um mecanismo extremo de acabar com a dor psíquica, devido a uma ausência de repertório psicológico para lidar com os problemas, decorrendo no ato como uma estratégia de fuga.

Noutro estudo ${ }^{37}$ verificou-se que quem pratica o suicídio não busca a morte em si. Outros trabalhos também revelam que, nessas tentativas, há o desenvolvimento de fantasias nas quais, $\mathrm{o}$ ato não tem como perspectiva encerrar a vida, mas sim a transformação do sofrimento psíquico por meio de uma ruptura extrema ${ }^{6,36,38,39}$.

Outra investigação o suicídio representado por termos: sofrimento, fuga e desespero, defendendo-se como ponto comum entre as representações desses grupos a ideia de que as pessoas se matam porque só encontram essa única saída para lidar com seu estado de sofrimento ${ }^{36,40}$, devido a uma rigidez de pensamento que impede outras possibilidades ${ }^{41}$.

Um estudo apresentou o suicídio vinculado a sofrimento, desespero, fuga e doenças. Entre os participantes do mesmo estudo, outro grupo de pessoas sem conhecimento do tema, relataram representações de fuga, desespero, covardia, nervosismo e chamamento de atenção ${ }^{42}$.

0 ato suicida não pode ser considerado racional e consciente, já que as pessoas não buscam a morte de forma voluntária sem que a sua estrutura cognitiva tenha a morte como meta ${ }^{43}$. É possível que esse argumento esteja relacionado com o fato de que as tentativas de suicídio ultrapassam em 10 vezes a consumação do ato ${ }^{14}$.

Com relação à associação que os participantes fizeram entre psicopatologias e ideação suicida, alguns estudos argumentam que sintomas depressivos são fortes preditores do suicídio $^{44-46}$. As pesquisas tem se divido entre aquelas que atribuem o ato suicida aos transtornos de ordem mental e outras que não fazem correlação com fatores psicopatológicos ${ }^{47-49}$. No entanto, há pesquisadores que criticam a causalidade do suicídio na 
dinâmica dos transtornos psíquicos com suporte na medicina e na farmacologia modernas, haja vista que tais resultados têm-se mostrado reducionistas para a abordagem desse fenômeno complexo e multicausal ${ }^{50}$.

No caso de influências externas o termo pressão é presente no núcleo central das representações. De modo geral, há estudos que atribuem o comportamento suicida a fatores disposicionais - cujos fundamentos residem na dinâmica interna da pessoa -, ao passo que há outros estudos que o associam a fatores situacionais com causalidade externa ${ }^{10,14,24}$. Alguns fatores situacionais se associam ao risco de suicídio, tais como: estresse, conflitos interpessoais, ausência de suporte social e eventos traumáticos ${ }^{35}$.

Os estudantes apontaram que a família e o círculo social mais próximo têm um papel fundamental de suporte social para aqueles que possuem um potencial risco suicida. Também, a solidão e o isolamento foram apontados como fatores associados ao suicídio, devido ao sofrimento psíquico não reconhecido e ao não cumprimento das expectativas sociais. Outros trabalhos apontam que há uma correlação entre a dinâmica social externa e o plano interno do sujeito, tendo em vista que, em diferentes grupos sociais, os transtornos psíquicos explicam significativamente o risco de suicídio ${ }^{46-48}$.

0 impacto de um suicídio é alto para as famílias envolvidas, afetando entre 5 a 10 pessoas $^{2,13,25}$. 0 estigma social, a culpa e o abandono são sentimentos frequentemente relatados pelos familiares sobreviventes, os quais passam a se tornar potenciais grupos de risco ${ }^{24}$. Tais sentimentos constituem-se barreiras de acesso ao apoio necessário para a experiência social do processo de luto ${ }^{10,23,27}$.

Assim como acontecia em casos de familiares mortos em decorrência do vírus da AIDS, os familiares relatam que se sentem constrangidos em vivenciar o luto publicamente, pois este não é reconhecido ou autorizado ${ }^{2}$. No caso de mulheres, esse sentimento conduz à ideia de fracasso, já que sentem que não desempenharam adequadamente seus papeis de cuidadoras 51,52 .

Esses tabus são o fundamento para o desenvolvimento de doenças psiquiátricas e outros problemas graves de saúde 23 :

"Os sobreviventes poderão encontrar dificuldades para retomar suas vidas após o ocorrido, isolando-se para evitar possíveis julgamentos sociais, além de apresentar vergonha e sensações ambivalentes que os tornam cerca de duas a três vezes mais suscetíveis ao risco de suicídio ${ }^{1}$.

\section{CONCLUSÃo}

A pesquisa acerca de temáticas socialmente sensíveis, como o suicídio, é pertinente para a instrumentalização de intervenções apropriadas pelos profissionais que lidam com esse fenômeno na clínica e na cultura. Além disso, a compreensão desse conhecimento prático que as pessoas constroem sobre o suicídio possibilita que essas intervenções estejam mais condizentes com a dinâmica psicossocial do grupo em questão, pois as representações variam de acordo com o plano em que estão sendo formuladas.

No caso dos estudantes de psicologia, as representações partilhadas sobre o tema são marcadas por cognemas que associam o ato suicida a transtornos com sintomatologia clínica. É preciso que a formação de profissionais da saúde leve em consideração os intrincados fatores que permeiam a temática, para uma atuação prática, que não seja reducionista e limitada.

O suporte psicológico e interdisciplinar é fundamental para o atendimento a pessoas que apresentam desejos ou comportamentos suicidas. Em virtude disso, os profissionais de saúde mental desempenham papel essencial para o acolhimento e a tratamento de pessoas que possuem pensamentos, ideações ou que já tentaram praticar o ato suicida. É necessário que sejam realizados estudos que visem a compreensão das crenças desses profissionais, com vistas a instrumentaliza-los para lidar com esse fenômeno de uma forma mais eficiente e adequada.

Do mesmo modo, os estudantes representaram o suicídio como uma forma de lidar com o sofrimento psíquico, buscando não à morte, mas o fim da dor. Por essa razão, novos estudos 
devem ser empreendidos, visando compreender o pensamento partilhado sobre morte e sofrimento psíquico. Quais são as principais crenças que fundamentam o ato suicida como uma forma de lidar com o sofrimento psíquico? Qual é o papel das famílias e do círculo social para a prevenção e o risco do suicídio? Essas questões são prementes para as próximas investigações acerca dessa temática.

Dentre as limitações desse estudo, destaca-se a quantidade de respondentes que poderia ser mais ampla, com perspectivas interpretativas maiores. Além disso, outras análises quantitativas, como a aplicação de instrumentos de atitudes, poderiam ter sido empregadas, a fim de se ampliar a compreensão do fenômeno.

\section{REFERÊNCIAS}

1. Ruckert MLT, Frizzo RP, Rigoli MM. Suicídio: a importância de novos estudos de posvenção no Brasil. Rev Bras Ter Cogn. [Internet]. 2019 [citado em 18 nov 2020]; 15(2):85-91. Disponível em: http://pepsic.bvsalud.org/pdf/rbtc/v15n2/v15n2a02.pdf. DOI: 10.5935/1808-5687.20190013

2. Sebastião MASS. Vida depois da morte: narrativas da experiência de perda de um familiar por suicídio [Internet]. [dissertação]. Évora, Portugal: Escola de Ciências Sociais; 2017. https://core.ac.uk/download/pdf/80518262.pdf

3. Alves Júnior CAS, Nunes HEG, Gonçalves ECA, Silva DAS. Suicidal behaviour in adolescents: characteristics and prevalence. J Hum Growth Dev. [Internet]. 2017 [citado em 18 nov 2020]; 26(1):8894. Disponível em: http://pepsic.bvsalud.org/pdf/rbcdh/v26n1/13.pdf. http://dx.doi.org/10.7322/jhgd.113733

4. Rheinreimer B, Kunz M. Atenção ao suicídio. Clin Biomed Res. [Internet]. 2015 [citado em 18 nov 2020]; 35(3):123-5. Disponível em: https://seer.ufrgs.br/hcpa/article/view/60044

5. Santos CVM. Sofrimento psíquico e risco de suicídio: diálogo sobre saúde mental na universidade. Rev NUFEN [Internet]. 2019 [citado em 18 nov 2020]; 11(2):149-60. Disponível em: http://pepsic.bvsalud.org/pdf/rnufen/v11n2/a10.pdf. DOI: 10.26823/RevistadoNUFEN.vol11.n02rex29

6. Cortez PA, Veiga HMS, Gomide APA, Souza MVR. Suicídio no trabalho: um estudo de revisão da literatura brasileira em psicologia. Rev Psic, Organ Trab. [Internet]. 2019 [citado em 18 nov 2020]; 19(1):523-31. Disponível em: http://pepsic.bvsalud.org/pdf/rpot/v19n1/v19n1a03.pdf. DOI: 10.17652/rpot/2019.1.14480

7. Associação Brasileira de Psiquiatria. Suicídio: informando para prevenir [Internet]. Brasília, DF: Conselho Federal de Medicina; 2014. Disponível em: https://www.hsaude.net.br/wpcontent/uploads/2020/09/Cartilha-ABP-Preven\%C3\%A7\%C3\%A3o-Suic\%C3\%ADdio.pdf

8. Costa SP, Chavaglia SRR, Amaral EMS, Silveira RE. Internações e gastos relacionados ao suicídio em um hospital público de ensino. Rev Enferm Atenção Saúde [Internet]. 2015 [citado em 18 nov 2020]; $4(2): 20-32$. Disponível

http://seer.uftm.edu.br/revistaeletronica/index.php/enfer/article/view/1104

9. Durkheim E. O suicídio: estudo sociológico. Lisboa: Editorial Presença; 1977.

10. Benetti IC, Molina LR, Kornin A. Características do suicídio em Santa Catarina: um estudo do período de 2007 a 2016. Estud Psicol. (Natal) [Internet]. 2018 [citado em 18 nov 2020]; 23(4): 404-15. Disponível em: http://pepsic.bvsalud.org/pdf/epsic/v23n4/a07v23n4.pdf. DOI: http://dx.doi.org/10.22491/1678-4669.20180038

11. Costanza A, Ambrosetti J, Wyss K, Bondolfi G, Sarasin F, Khan R. Prévenir le suicide aux urgences: de la Théorie Interpersonnelle du Suicide à la connectedness. Rev Med Suisse [Internet]. 2018 [citado em 18 nov 2020]; 14(593):335-8. Disponível em: https://archive-ouverte.unige.ch/unige:111013

12. World Health Organization. World health statistics 2018: monitoring health for the SDGs Sustainable Development Goals [Internet]. Geneva: World Health Organization; 2018 [citado em 18 nov 2020]. Disponível em: https://www.who.int/docs/default-source/gho-documents/world-health-statisticreports/6-june-18108-world-health-statistics-2018.pdf

13. Fukumitsu KO, Kovács MJ. Especificidades sobre processo de luto frente ao suicídio. Psico [Internet]. 2016 [citado em 18 nov 2020]; 47(1):3-12. Disponível em: http://pepsic.bvsalud.org/pdf/psico/v47n1/02.pdf. DOI: http://dx.doi.org/10.15448/19808623.2015.2.17484 
14. Silva NKN, Carvalho CMS, Magalhães JM, Carvalho Junior JAM, Sousa BVS, Moreira WC. Ações do enfermeiro na atenção básica para prevenção do suicídio. SMAD, Rev Eletrônica Saúde Mental Álcool Drog. [Internet]. 2017 [citado em 18 nov 2020]; 13(2):71-7. Disponível em: http://pepsic.bvsalud.org/pdf/smad/v13n2/03.pdf DOI: 10.11606/issn.1806-6976.v13i2p71-77

15. Ferracioli NGM, Oliveira-Cardoso EAV, Vedana KGG, Pillon SC, Miasso AIS, Souza J, et al. Os bastidores psíquicos do suicídio: uma compreensão psicanalítica. Vínculo [Internet]. 2019 [citado em 18 nov 2020]; 16(1):1-17. Disponível em: http://pepsic.bvsalud.org/pdf/vinculo/v16n1/v16n1a03.pdf DOI: http://dx.doi.org/10.32467/issn.1982-1492v16n1p17-28

16. Cordeiro EL, Silva LSR, Mendes EWP, Silva LCL, Duarte VL, Lima ECMP. Tentativa de suicídio e fatores associados ao padrão uso e abuso do álcool. SMAD, Rev Eletrônica Saúde Mental Álcool Drog. [Internet]. 2020 [citado em 18 nov 2020]; 16(1):1-10. DOI: https://doi.org/10.11606//issn.18066976.smad.2020.157007

17. Leme VBR, Chagas APSPS, Alves AJCP, Rocha CS, França FA, Jesus FQS, et al. Habilidades sociais e prevenção do suicídio: relato de experiência em contextos educativos. Estud Pesqui Psicol. [Internet]. 2019 [citado em 18 nov 2020]; 19(1):284-97. Disponível em: https://www.epublicacoes.uerj.br/index.php/revispsi/article/view/43020/29667

18. Couto VVD, Tavares MSA. Apego e risco de suicídio em adolescentes: estudo de revisão. Rev SPAGESP [Internet]. 2016 [citado em 18 nov 2020]; 17(2):120-36. Disponível em: http://pepsic.bvsalud.org/pdf/rspagesp/v17n2/v17n2a10.pdf

19. Sheftall AH, Mathias CW, Furr RM, Dougherty DM. Adolescent attachment security, family functioning, and suicide attempts. Attch Hum Dev. [Internet]. 2013 [citado em 18 nov 2020]; 15(4):36883. Disponível em: https://pubmed.ncbi.nlm.nih.gov/23560608/. DOI: 10.1080/14616734.2013.782649

20. Cruz D, Narciso I, Pereira C, Sampaio D. Self-destructive symptomatic frames in clinical adolescents: is the same different? J Res Adolesc. [Internet]. 2015 [citado em 18 nov 2020]; 25(3):524-33. Disponível em: https://onlinelibrary.wiley.com/doi/abs/10.1111/jora.12152. DOI: https://doi.org/10.1111/jora.12152

21. Saffer BY, Glenn CR, Klonsky ED. Clarifying the relationship of parental bonding to suicide ideation and attempts. Suicide Life Threat Behav. [Internet]. 2015 [citado em 18 nov 2020]; 45(4):518-28. Disponível em: https://www2.psych.ubc.ca/ klonsky/publications/PBI_2015.pdf. DOI: $10.1111 /$ sltb. 12146

22. Levinzon GK. Thirteen reasons why: suicídio em adolescentes. J Psicanal. [Internet]. 2018 [citado em 18 nov 2020]; 51(95):297-306. Disponível em: http://pepsic.bvsalud.org/pdf/jp/v51n95/v51n95a24.pdf

23. Rocha PG, Lima DMA. Suicídio: peculiaridades do luto das famílias sobreviventes e a atuação do psicólogo. Psicol Clín. [Internet]. 2019 [citado em 18 nov 2020]; 31(2):323-44. Disponível em: http://pepsic.bvsalud.org/pdf/pc/v31n2/07.pdf DOI: http://dx.doi.org/10.33208/PC19805438V0031N02A06

24. Botega NJ. Crise suicida: avaliação e manejo. Porto Alegre: Artmed; 2017.

25. Baére F, Zanello, V. O gênero no comportamento suicida: uma leitura epidemiológica dos dados do Distrito Federal. Estud Psicol. (Natal) [Internet]. 2018 [citado em 19 nov 2020]; 23(2):168-78. Disponível em: http://pepsic.bvsalud.org/pdf/epsic/v23n2/a08v23n2.pdf DOI: 10.22491/16784669.20180017

26. Yehudit S. Choosing to enter the darkness - a researcher's reflection on working with suicide survivors: a collage of words and images. Qual Res Psychol. [Internet]. 2018 [citado em 18 nov 2020]; 17:1-12. Disponível em: https://www.tandfonline.com/doi/abs/10.1080/14780887.2018.1442766 DOI: https://doi.org/10.1080/14780887.2018.1442766

27. Moscovici S. A representação social da psicanálise. Petrópolis, RJ: Vozes; 2012.

28. Abric JC. Abordagem estrutural das representações sociais: desenvolvimentos recentes. In: Campos PHF, Loureiro MCS, editores. Representações sociais e práticas educativas. Goiânia: UCG; 2003. p. 3757.

29. Moscovici S. Representações sociais: investigações em psicologia social. Petrópolis, RJ: Vozes; 2005. 30. Jesuino JC. Ser professor não é fácil. Educ Quest. [Internet]. 2014 [citado em 18 nov 2020]; 49(35):2948. DOI: https://doi.org/10.21680/1981-1802.2014v49n35ID5903 
31. Menin MSS. Representação social e estereótipo: a zona muda das representações sociais. Psicol Teor Pesqui. [Internet]. 2006 [citado em 18 nov 2020]; 22(1):1-26. Disponível em: https://www.scielo.br/pdf/ptp/v22n1/29843.pdf

32. Vieira KFL, Coutinho MPL. Representações sociais da depressão e do suicídio elaboradas por estudantes de psicologia. Psicol Ciênc Prof. [Internet]. 2008 [citado em 18 nov 2020]; 28(4):71427. Disponível em: https://www.scielo.br/pdf/pcp/v28n4/v28n4a05.pdf

33. Ministério da Saúde (Br). Diretrizes do apoio integrado para a qualificação da gestão e da atenção no SUS [Internet]. Brasília, DF: Ministério da Saúde; 2012 [citado em 14 set 2019]. Disponível em: http://portalarquivos.saude.gov.br/images/pdf/2015/julho/15/Diretrizes-Apoio-Integrado-MS1007-12.pdf

34. Wolter RP, Wachelke J. Índices complementares para o estudo de uma representação social a partir de evocações livres: raridade, diversidade e comunidade. Psicol Teor Prát. [Internet]. 2013 [citado em 18 nov 2020]; 15(2):119-29. Disponível em: http://pepsic.bvsalud.org/pdf/ptp/v15n2/09.pdf

35. Wolter RP, Wachelke J, Naiff D. A abordagem estrutural das representações sociais e o modelo dos esquemas cognitivos de base: perspectivas teóricas e utilização empírica. Temas Psicol. [Internet]. 2016 [citado em dez 2020]; 24(3):1139-52. Disponível http://pepsic.bvsalud.org/pdf/tp/v24n3/v24n3a18.pdf

36. Correia CM, Gomes NP, Couto TMR, Diniz EAL, Diniz NMF. Representações sobre o suicídio para mulheres com história de violência doméstica e tentativa do mesmo. Texto \& Contexto Enferm. [Internet]. 2014 [citado em 18 nov 2020]; 23(1):118-25. Disponível em: https://www.scielo.br/pdf/tce/v23n1/pt_0104-0707-tce-23-01-00118.pdf

37. Cremasco GS, Baptista MN. Depressão, motivos para viver e o significado do suicídio em graduandos do curso de psicologia. Estud Interdiscip Psicol. [Internet]. 2017 [citado em 18 nov 2020]; 8(1):2237. Disponível em: http://www.uel.br/revistas/uel/index.php/eip/article/view/24293/0

38. Cassorla RMS. Suicídio: fatores inconscientes e aspectos socioculturais: uma introdução. São Paulo: Blucher; 2017.

39. Müller SA, Pereira G, Zanon RB. Estratégias de prevenção e pósvenção do suicídio: estudo com profissionais de um Centro de Atenção Psicossocial. Rev Psicol IMED [Internet]. 2017 [citado em 18 nov 2020]; 9(2):6-23. Disponível em: http://pepsic.bvsalud.org/pdf/rpi/v9n2/02.pdf

40. Freitas APA, Borges LM. Tentativas de suicídio e profissionais de saúde: significados possíveis. Estud Pesqui Psicol. [Internet]. 2014 [citado em 18 nov 2020]; 14(2):560-77. Disponível em: http://pepsic.bvsalud.org/pdf/epp/v14n2/v14n2a10.pdf

41. Correia CM, Diniz NMF, Gomes NP, Andrade ICS, Campos LM, Carneiro JB. Sinais de risco para o suicídio em mulheres com história de violência doméstica. SMAD, Rev Eletrônica Saúde Mental Álcool Drog. [Internet]. 2018 [citado em 18 nov 2020]; 14(4):219-25. Disponível em: http://pepsic.bvsalud.org/pdf/smad/v14n4/05.pdf. $\quad$ DOI: $\quad$ 10.11606/issn.18066976.smad.2018.151401

42. Daolio ER, Silva JV. Os significados e os motivos do suicídio: as representações sociais de pessoas residentes em Bragança Paulista, SP. Bioethikos [Internet]. 2009 [citado em 18 nov 2020]; 3(1):68-76. Disponível em: www.saocamilo-sp.br/pdf/bioethikos/68/68a76.pdf

43. Brunhari MV, Darriba VA. O suicídio como questão: melancolia e passagem ao ato. Psicol Clín. [Internet]. 2014 [citado em 18 nov 2020]; 26(1):197-213. Disponível em: http://pepsic.bvsalud.org/pdf/pc/v26n1/13.pdf

44. Vieira KFL. Depressão e suicídio: uma abordagem psicossociológica no contexto acadêmico [Internet]. [dissertação]. João Pessoa: Universidade Federal da Paraíba; 2008 [citado em 18 nov 2020]. Disponível

http://www.cchla.ufpb.br/ppgp/images/pdf/dissertacoes/kay_francis_leal_vieira_2008.pdf

45. Borges VR, Fensterseifer L. Fatores de risco ou proteção para a presença de ideação suicida na adolescência. Interam J Psychol. [Internet]. 2005 [citado em 18 nov 2020]; 39(2):259-66. Disponível em: https://www.researchgate.net/publication/26610518_Fatores_de_Risco_ou_Protecao_para_a_Presenc ade_Ideacao_Suicida_na_Adolescencia

46. Dutra E. Suicídio de universitários: o vazio existencial de jovens na contemporaneidade. Estud Pesqui Psicol. [Internet]. 2012 [citado em 18 nov 2020]; 12(3):924-37. Disponível em: http://pepsic.bvsalud.org/pdf/epp/v12n3/v12n3a13.pdf 
47. Pereira AAM. Dor psicológica e ideação suicida em estudantes [Internet]. [dissertação]. Aveiro, Portugal: Universidade de Aveiro; 2013 [citado em 18 nov 2020]. Disponível em: http://hdl.handle.net/10773/11527

48. Pereira AAG. Ideação suicida e fatores associados: estudo realizado numa amostra da população universitária da Universidade de Trás-os-Montes e Alto Douro. [dissertação]. Vila Real, Portugal: Universidade de Trás-os-Montes e Alto Douro; 2011.

49. Yoon J, Lau AS. Maladaptive perfectionism and depressive symptoms among Asian American college students: contributions of interdependence and parental relations. Cultur Divers Ethnic Minor Psychol. [Internet]. 2008 [citado em 18 nov 2020]; 14(2):92-101. Disponível em: https://psycnet.apa.org/record/2008-04404-002. DOI: https://doi.org/10.1037/1099-9809.14.2.92 50. Santos MA. Câncer e suicídio em idosos: determinantes psicossociais do risco, psicopatologia e oportunidades para prevenção. Cienc Saúde Colet. [Internet]. 2017 [citado em 18 nov 2020]; 22(9):3061-75. Disponível em: https://www.scielo.br/pdf/csc/v22n9/1413-8123-csc-22-093061.pdf. DOI: $10.1590 / 1413-81232017229.05882016$

51. Nunes F, Pinto J, Lopes M, Enes C, Botti NCL. O fenômeno do suicídio entre os familiares sobreviventes: revisão integrativa. Rev Port Enferm Saúde Mental [Internet]. 2016 [citado em 18 nov 2020]; 15:17-22. Disponível em: http://www.scielo.mec.pt/pdf/rpesm/n15/n15a03.pdf. DOI: http://dx.doi.org/10.19131/rpesm.0127

52. Batista P, Santos JC. Processo de luto dos familiares de idosos que se suicidaram. Rev Port Enferm Saúde Mental [Internet]. 2014 [citado em 18 nov 2020]; 12:17-24. Disponível em: http://www.scielo.mec.pt/pdf/rpesm/n12/n12a03.pdf

Editora Associada: Vania Del Arco Paschoal

\section{CONTRIBUIÇÕES}

Otávio Henrique Braz de Oliveira Calil contribuiu no desenho, análise de dados e redação. Daniela Scheinkman Chatelard participou da revisão.

\section{Como citar este artigo (Vancouver)}

Calile OHBO, Chatelard DS. Representações sociais sobre suicídio. REFACS [Internet]. 2021 [citado em inserir dia, mês e ano de acesso]; 9(2):358-71. Disponível em: inserir link de acesso. DOI: inserir link do DOI

\section{Como citar este artigo (ABNT)}

CALILE, O. H. B. O.; CHATELARD, D. S. Representações sociais sobre suicídio. REFACS, Uberaba, MG, v. 9, n. 2, p. 358-71, 2021. DOI: inserir link do DOI. Disponível em: inserir link de acesso. Acesso em: inserir dia, mês e ano de acesso.

\section{Como citar este artigo (APA)}

Calile, O.H.B.O., \& Chatelard, D.S. (2021). Representações sociais sobre suicídio. REFACS, 9(2), 358-71. Recuperado em inserir dia, mês e ano de acesso de inserir link de acesso. DOI: inserir link do DOI. 